\title{
Cocaine Self-Administration in Mice Is Inversely Related to Phosphorylation at Thr34 (Protein Kinase A Site) and Ser130 (Kinase CK1 Site) of DARPP-32
}

\author{
Y. Zhang, ${ }^{1}$ P. Svenningsson, ${ }^{2}$ R. Picetti, ${ }^{1}$ S. D. Schlussman, ${ }^{1}$ A. C. Nairn,${ }^{2,3}$ A. Ho, ${ }^{1}$ P. Greengard, ${ }^{2}$ and M. J. Kreek ${ }^{1}$ \\ ${ }^{1}$ The Laboratory of the Biology of Addictive Diseases and ${ }^{2}$ The Laboratory of Molecular and Cellular Neuroscience, The Rockefeller University, New York, \\ New York 10021, and 3Department of Psychiatry, Yale University School of Medicine, New Haven, Connecticut 06508
}

The reinforcing effect of cocaine is associated with increases in dopamine in the striatum. The phosphoprotein DARPP-32 (dopamineand cAMP-regulated phosphoprotein) has been shown to mediate the intracellular events after activation of dopamine receptors. DARPP-32 is phosphorylated at multiple sites by different protein kinases, but little is known about the functional role of these different sites. Cocaine self-administration and striatal levels of dopamine after acute "binge" cocaine administration were measured in separate lines of mice with alanine mutations introduced into DARPP-32 at either Thr34 (protein kinase A site, Thr34A), Thr75, (cyclin-dependent kinase 5 site, Thr75A), Ser97 (kinase CK2 site, Ser97A), or Ser130 (kinase CK1 site, Ser130A). Acquisition of stable cocaine selfadministration required significantly more time in Thr34A-I- mice. Both Thr34A- and Ser130A-DARPP-32 mutant mice selfadministered more cocaine than their respective wild-type controls. Also, cocaine-induced increases of dopamine in dorsal striatum were attenuated in the Thr34A- and Ser130A-DARPP-32 phosphomutant mice compared with wild-type mice. Notably, levels of P-Thr34- and P-Ser130-DARPP-32 were reduced after self-administration of cocaine in wild-type mice. Thus, phosphorylation states of Thr34- and Ser130-DARPP-32 play important roles in modulating the reinforcing effects of cocaine.

Key words: DARPP-32; phosphorylation; mutation; cocaine; self-administration; dopamine

\section{Introduction}

The reinforcing property of cocaine is associated with increases in extracellular dopamine in the striatum. Cocaine enhances dopamine levels by interrupting dopamine reuptake (Koe, 1976). Dopamine activates both $\mathrm{D}_{1^{-}}$and $\mathrm{D}_{2}$-like receptors, resulting in either activation or inhibition of adenylyl cyclase/cAMP/protein kinase A (PKA) signaling, respectively (Stoof and Kebabian, 1981). A major substrate for PKA in the striatum is dopamineand cAMP-regulated phosphoprotein (DARPP-32) (Walaas et al., 1983; Fienberg et al., 1998; Greengard, 2001). DARPP-32 is highly concentrated in the medium spiny neurons of the striatum (Ouimet et al., 1984), where it plays a central role in integrating glutamatergic and dopaminergic neurotransmission originating from the cerebral cortex and the substantia nigra pars compacta/ ventral tegmental area, respectively (Greengard, 2001).

The function of DARPP-32 has been shown to be regulated by four different phosphorylation sites (supplemental figure, available at www.jneurosci.org as supplemental material) (for review,

Received May 12, 2005; revised Jan. 11, 2006; accepted Jan. 13, 2006.

This work was supported by National Institutes of Health (NIH)-National Institute on Drug Abuse (NIDA) Grant DA10044 (P.G., A.C.N.) and by NIH-NIDA Research Center Grant P60-DA05130 and NIDA Research Scientist Award K05-DA00049 (M.J.K.). We thank Drs. Eduardo Butelman and Yan Zhou for their helpful discussions and assistance in this project. We thank Dr. Feng Liu for the generous gift of the Ser97-DARPP-32 antibody.

Correspondence should be addressed to Dr. Yong Zhang, The Laboratory of the Biology of Addictive Diseases, The Rockefeller University, 1230 York Avenue, Box 171, New York, NY 10021. E-mail: zhangyo@mail.rockefeller.edu. DOI:10.1523/JNEUROSCI.3923-05.2006

Copyright $\odot 2006$ Society for Neuroscience $\quad$ 0270-6474/06/262645-07\$15.00/0 see Svenningsson et al., 2004). Phosphorylation at Thr34, by PKA, converts DARPP-32 into a potent inhibitor of protein phosphatase-1 (PP-1) (Walaas et al., 1983). Phosphorylation at Thr75, by cyclin-dependent kinase 5 (Cdk5), switches DARPP-32 into an inhibitor of PKA (Bibb et al., 1999). Phosphorylation at Ser97, by CK2 (formerly casein kinase 2), enhances the ability of PKA to phosphorylate DARPP-32 at Thr34 (Girault et al., 1989), whereas phosphorylation at Ser130, by CK1 (formerly casein kinase 1), inhibits dephosphorylation at Thr34 by protein phosphatase 2B (PP-2B) (Desdouits et al., 1995).

It was shown in previous studies that acute intraperitoneal administration of cocaine results in increased phosphorylation of Thr34-DARPP-32 and decreased phosphorylation at Thr75DARPP-32 in the neostriatum (Nishi et al., 2000). In contrast, repeated intraperitoneal administration of cocaine increased levels of P-Thr75 and decreased levels of P-Thr34 of DARPP-32 (Bibb et al., 2001). Consistent with the opposing effects of acute and chronic cocaine on its phosphorylation, DARPP-32 has different roles in acute and chronic effects of cocaine on locomotion. The increases in locomotor activity caused by acute cocaine administration are attenuated in DARPP-32 knock-out (KO) mice under certain conditions (Fienberg et al., 1998). In contrast, the locomotor sensitization found after repeated cocaine administration is enhanced in DARPP-32 KO mice (Hiroi et al., 1999).

The purpose of the present studies was to investigate the role that each phosphorylation site of DARPP-32 plays in the rewarding effect of cocaine. First, we examined self-administration of 
cocaine in four lines of mice in which Thr34-, Thr75-, Ser97-, or Ser130-DARPP-32 was replaced by alanine to prevent phosphorylation at those sites of DARPP-32 (Svenningsson et al., 2003). We measured the number of days each phosphomutant mouse line took to acquire cocaine self-administration and the number of infusions the mice self-administered with varied doses of cocaine. Second, we measured P-Thr34-, P-Thr75, P-Ser97, and P-Ser130-DARPP-32 in striatal homogenates from wild-type mice that had self-administered cocaine. Third, we measured basal levels and changes in dopamine levels after acute "binge" cocaine administration in the dorsal and ventral striatum in the Thr34A-, Thr75A-, and Ser130A-DARPP-32 phosphomutant lines.

\section{Materials and Methods \\ Mice}

Mice each bearing a mutation in which Thr34, Thr75, or Ser130 was replaced by a nonphosphorylatable alanine were obtained from heterozygous animals generated from C57BL/6 × 129 SV hybrids that had been backcrossed for two generations on a C57BL/6 background (Svenningsson et al., 2003; Andersson et al., 2005; Zachariou et al., 2005). Ser97A-DARPP-32 phosphomutant mice were obtained from heterozygous animals generated from C57BL/ $6 \times 129 \mathrm{SV}$ hybrids that had been backcrossed for one generation on a C57BL/6 background.

All experiments were performed in 2- to 4-month-old homozygotic mutants and their wild-type siblings. Animal care and experimental procedures were conducted according to the Guide for the Care and Use of Laboratory Animals. The experimental protocols were approved by the Institutional Animal Care and Use Committee of The Rockefeller University.

\section{Self-administration of cocaine}

Catheter implantation. The mice were anesthetized with a combination of xylazine $(8.0 \mathrm{mg} / \mathrm{kg}$, i.p. $)$ and ketamine $(80 \mathrm{mg} / \mathrm{kg}$, i.p. $)$. After shaving and application of a $70 \%$ alcohol and iodine preparatory solution, incisions were made in the midscapular region and anteromedial to the forearm. A catheter (inner diameter, $0.31 \mathrm{~mm}$; outer diameter, $0.64 \mathrm{~mm}$ ) was passed subcutaneously from the dorsal to the ventral incision. After exposure of the right jugular vein, a 22 gauge needle was inserted into the vein to guide the catheter into the jugular vein. Once the catheter was inside the vein, the needle was removed and the catheter was inserted to the level of a marker $1.1 \mathrm{~cm}$ from the end. The catheter was tied to the vein with surgical silk. Physiological saline then was flushed through the catheter to avoid clotting and then the catheter was capped with a stopper. Antibiotic ointment was applied to the catheter exit wound on the animal's back and forearm. Animals were allowed to have $4-5 \mathrm{~d}$ of recovery before being placed in operant test chambers for the selfadministration procedure.

\section{Intravenous self-administration chamber}

The self-administration chamber ENV-307W $(21.6 \times 17.8 \times 12.7 \mathrm{~cm}$; Med Associates, Burlington, VT) was located inside a larger box (Med Associates, Georgia, VT). The front, back, and top were constructed of $5.6 \mathrm{~mm}$ polycarbonate. Each chamber contained a wall with two small holes $(0.9 \mathrm{~cm}$ diameter, $4.2 \mathrm{~cm}$ apart, $1.5 \mathrm{~cm}$ from the floor of the chamber). One hole was defined as active, and the other was inactive. When the photocell in the active hole was triggered by a nose poke, the infusion pump (Med Associates) delivered an infusion of $20 \mu \mathrm{l} / 3 \mathrm{~s}$ from a $5 \mathrm{ml}$ syringe. During infusion, a cue light above the active hole was illuminated. Each injection was followed by a $20 \mathrm{~s}$ "time-out" period during which poking responses were recorded but had no programmed consequences. All responses at the inactive hole were also recorded. The syringe was connected by a swivel via Tygon tubing. The infusion pump and syringe were outside the chamber.

\section{Acquisition criteria and training}

A 2 h self-administration session was conducted once a day, with six sessions per week. During the first session, mice were placed in the selfadministration chamber, and a nose poke through the active hole led to an injection of saline. Starting with the second session, infusion of cocaine $(1.0 \mathrm{mg} / \mathrm{kg})$ was available under a fixed ratio 1 (FR1) schedule. The FR schedule was changed from FR1 to FR3 after reaching the selfadministration criteria: (1) stable intake, defined as two consecutive sessions in which the total number of infusions per session remained within $20 \%$ of the mean of these two consecutive sessions; (2) the percentage of responses on the active hole versus the inactive hole were $>70 \%$ in these two consecutive sessions; and (3) the minimum infusion number was 10/session in the two sessions. The FR3 schedule was maintained until the mice reached the full self-administration criteria: (1) stable intake, defined as three consecutive sessions (rather than two sessions in FR1) in which the total number of infusions per session remained within $20 \%$ of the mean of these three consecutive sessions; (2) the percentage of responses on the active hole were $>70 \%$ in these three consecutive sessions; and (3) the minimum infusion number was $10 /$ session in the three sessions.

Once the mice reached the full self-administration criteria, the doses of cocaine were presented in a descending order $(2.0,1.0,0.5$, and $0.1 \mathrm{mg} / \mathrm{kg}$ per infusion). We conducted the dose-response study from higher to lower doses to avoid extinction of nose poking at the active hole. Because it is difficult to maintain catheter patency for an extended period in mice, we tested each dose for only $2 \mathrm{~d}$. On the day the animals were killed, all animals had a final session at the training dose $(1.0 \mathrm{mg} / \mathrm{kg}$ per infusion). At the end of the experiment, only mice that passed a catheter patency test (defined as loss of muscle tone within a few seconds after administration of a short-acting anesthetic) were included in the selfadministration data analysis. Of a total 106 mice started in the studies, 88 mice reached full acquisition criteria. Of these 88 mice, 58 finished the dose-response study and passed the catheter patency test.

\section{Phosphorylation of DARPP-32 in wild-type animals that \\ self-administered cocaine}

We conducted a pilot study of the effect of cocaine on each phosphorylation site with wild-type mice that had undergone the full selfadministration procedure and a control group of similar mice with $5 \mathrm{~d}$ of experimenter-administered intraperitoneal saline injections. The results of this study showed that levels of P-Thr34-DARPP-32 and P-Ser130DARPP-32 in the striatum were significantly reduced in mice that had self-administered cocaine (data not shown). To verify these results, in a separate study, male wild-type littermates of each of the four phosphomutant lines that underwent the full cocaine self-administration paradigm described above were compared with control wild-type mice that received yoked saline infusions. Only the mice that passed the catheter patency test from both groups ( 15 of the 23 mice starting the study) were killed immediately after their last cocaine self-administration session by focused microwave irradiation (4.5-5 kW for $1.4 \mathrm{~s}$ ), using a small animal microwave (Muromachi Kikai, Tokyo, Japan). To optimize conditions for the microwave irradiation, the animals were put in a restraint chamber and placed at the same position in the instrument. The duration of the microwave procedure was between 10 and $15 \mathrm{~s}$. Brains were thereafter rapidly removed, and striata (including both caudate-putamen and nucleus accumbens) were dissected out and stored at $-80^{\circ} \mathrm{C}$. Frozen tissue samples were sonicated in boiling 1\% SDS. Equal amounts of protein were processed, using 10\% acrylamide gels as described previously (Nishi et al., 2000). Immunoblotting was performed using phosphorylation state-specific antibodies raised against Thr34-DARPP-32 (Snyder et al., 1992), Thr75-DARPP-32 (Bibb et al., 1999), Ser97-DARPP-32 (F. Liu and A. C. Nairn, unpublished data), Ser130-DARPP-32 (Liu et al., 2001) or an antibody against total DARPP-32 (Hemmings and Greengard, 1986), which is not phosphorylation state-specific. Antibody binding was detected by enhanced chemiluminescence (Amersham Biosciences, Piscataway, NJ) and quantified by densitometry, using NIH Image 1.61 software. The phosphoprotein levels were normalized against total protein levels.

\section{Microdialysis studies}

Three groups of mice from the phosphomutant lines Thr34A, Thr75A, and Ser130A were studied. An additional group of mixed wild-type mice from the Thr34A, Thr75A, and Ser130A phosphomutant lines served as a 
control (see Fig. 4 for details of the mixed group). Because of an insufficient number of wild-type controls from the Ser97A phosphomutant line for the microdialysis study, dialysis data from these mice are not included here. Of a total of 61 mice started in the microdialysis studies, the data from 54 were used in the final analyses.

\section{Guide cannula implantation}

Mice were anesthetized with a combination of xylazine $(8.0 \mathrm{mg} / \mathrm{kg}$, i.p. $)$ and ketamine $(80 \mathrm{mg} / \mathrm{kg}$, i.p.) and were placed in a stereotaxic frame modified for the mouse (David Kopf Instruments, Topanga, CA) for implantation of a guide cannula. Guide cannulas (CMA/7, North Chelmsford, MA) were implanted into the dorsal striatum [coordinates from bregma: anterior (A), $0.65 \mathrm{~mm}$; lateral (L), $\pm 2.00 \mathrm{~mm}$; ventral (V), $3.00 \mathrm{~mm}$ ] (Franklin and Paxinos, 1997) and ventral striatum (coordinates from bregma: A, $1.35 \mathrm{~mm}$;, $\pm 0.8 \mathrm{~mm}$;, $4.0 \mathrm{~mm}$ ) (Franklin and Paxinos, 1997). The guide cannulas were fixed to the skull by dental acrylic. Mice were allowed $4-5 \mathrm{~d}$ to recover from surgery before microdialysis.

\section{In vivo microdialysis}

Dialysis probes ( $2 \mathrm{~mm}$ active region; $\mathrm{CMA} / 7$ ) were calibrated for dopamine recovery in vitro before each experiment as described previously (Bergasa et al., 1997). On the day before each dialysis experiment, mice were individually placed into microdialysis chambers with free access to food and water. Dialysis probes were then lowered into the dorsal and ventral striatum. Probes were perfused with artificial CSF (in mм: 146 $\mathrm{NaCl}, 2.7 \mathrm{KCl}, 1.2 \mathrm{CaCl}_{2}, 1.0 \mathrm{MgCl}_{2}$ ) overnight at a rate of $1.0 \mu \mathrm{l} / \mathrm{min}$. After the overnight stabilization period (15-16 h), basal levels of dialysates were collected from the freely moving mice every $20 \mathrm{~min}$ for $1 \mathrm{~h}$ at a $1.0 \mu \mathrm{l} / \mathrm{min}$ flow rate. After collection of baseline samples, the animals received either binge pattern cocaine administration $(20 \mathrm{mg} / \mathrm{kg}$, i.p., three times at hourly intervals) or saline $(1 \mathrm{ml} / \mathrm{kg})$ in the same pattern. Dialysate samples were collected every $20 \mathrm{~min}$ throughout the cocaine/ saline administration period and for $3 \mathrm{~h}$ after the last injection. Samples were frozen and stored at $-80^{\circ} \mathrm{C}$ before dopamine analysis (Zhang et al., 2001, 2004).

Determination of dialysate dopamine levels

HPLC with electrochemical detection (ESA, North Chelmsford, MA) was used to measure dopamine concentration in the dialysates. The HPLC system consisted of an ESA 540 autosampler, an ESA 582 solvent delivery system, a reverse-phase C18 column and an ESA microdialysis cell (model 5014B). The MD-TD mobile phase (10\% acetonitrile) was purchased from ESA and was delivered at a rate of $0.5 \mathrm{ml} / \mathrm{min}$. Chromatograms were integrated and compared with standards using the ESA 501 chromatography system.

\section{Histological verification of probe placement}

Mice were decapitated after brief $\mathrm{CO}_{2}$ exposure at the end of each microdialysis study, and their brains were removed for histological evaluation. Frozen sections of $20 \mu \mathrm{m}$ were cut to verify the correct placement of dialysis probes after acetylcholinesterase labeling (Franklin and Paxinos, 1997). Figure 1 shows photomicrographs of a tissue section from the brain of a representative mouse used in this study, showing probe placement in the dorsal striatum (left) and in the ventral striatum (right).

\section{Data analysis}

One- or two-way ANOVAs were used to evaluate the significance of differences between phosphomutant lines of mice and wild-type controls in cocaine self-administration behaviors. In a separate cohort, a two-way ANOVA was used to assess the difference in response to binge pattern cocaine administration in three phosphomutant lines and a mixed wildtype control. ANOVA was used to compare the levels of P-Thr34-, P-Thr75-, P-Ser97-, and Ser130-DARPP-32 between mice that underwent cocaine self-administration and controls that received yoked saline infusions.

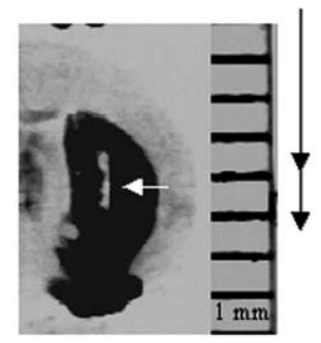

Bregma 0.62

(Franklin \& Paxinos, Fig. 26)

\section{Dorsal Striatum}

Figure 1. Placement of the dialysis probes. The micrograph in the left panel shows the probe placement in the dorsal striatum of a representative mouse in this study. The micrograph in the right panel shows the probe placement in the ventral striatum from a representative mouse in this study. Arrows indicate the track of the microdialysis probe, which extends $2 \mathrm{~mm}$ below the guide cannula. To the right of each figure, the top arrows indicate the extent of the guide cannula, and the bottom arrows approximate the microdialysis probe extending $2 \mathrm{~mm}$ beyond the guide cannula.

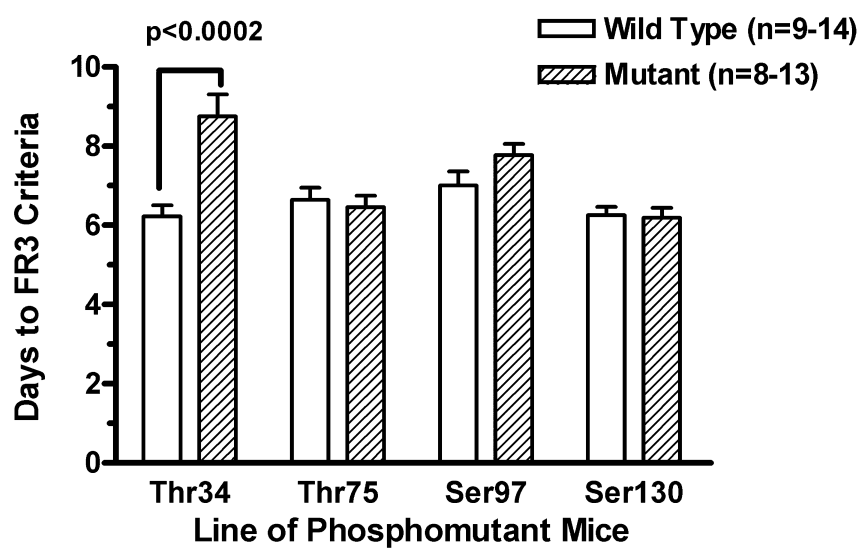

Figure 2. The effect of mutation of each separate phosphorylation site of DARPP-32 on acquisition of cocaine self-administration by mice of each phosphomutant line with its respective wild-type control is shown in Figure 2. Thr34A-DARPP-32 mutant mice took significantly longer to meet the full criteria for acquisition of cocaine self-administration (for details, see Materials and Methods) than did their wild-type controls (two-way ANOVA followed by Newman-Keuls post hoc tests). Error bars represent SEM.

\section{Results}

Mutation of Thr34-DARPP-32 to alanine affects acquisition of cocaine self-administration

We first measured the number of days each phosphomutant mouse line and its wild-type control took to acquire cocaine (1 $\mathrm{mg} / \mathrm{kg}$ per infusion) self-administration (Fig. 2). Thr34ADARPP-32 mutant mice took significantly longer to meet the criteria for acquisition of cocaine self-administration than did their wild-type controls ( $p<0.0002)$. Thr34A-DARPP-32 mutant mice reached the criteria in $8.8 \mathrm{~d}( \pm 0.6)$, whereas their wildtype controls took only $6.2 \mathrm{~d}( \pm 0.3)$. In contrast, there were no significant differences in time to reach the criteria for acquisition of cocaine self-administration between mutants and their wildtype controls in any of the other phosphomutant mouse lines. 
Mutation of either of two specific phosphorylation sites of DARPP-32 enhance response to lower doses of cocaine

Once mice met the full self-administration criteria, a dose-response study was performed in each of the four phosphomutant lines and their controls to determine whether mutation of any specific phosphorylation site on DARPP-32 would affect cocaine self-administration under an FR3 schedule. Figure 3 shows the number of self-administered cocaine or saline infusions at four different doses of cocaine $(2.0,1.0,0.5$, and $0.1 \mathrm{mg} / \mathrm{kg}$ per infusion; mean \pm SEM of two sessions at each dose) in each line of phosphomutant mice. Across all genotypes at the three higher doses, the total dose per session of cocaine self-administered was $9-43 \mathrm{mg} / \mathrm{kg}$, with an average of $23.8 \pm 5.9 \mathrm{mg} / \mathrm{kg}$.

Thr34A-DARPP-32 mice significantly exceeded their wild-type controls in a number of self-administered cocaine infusions at the dose of $0.5 \mathrm{mg} / \mathrm{kg}$ infusion. Ser130A-DARPP-32 mice selfadministered significantly greater numbers of cocaine infusions than did wild types at both the 0.5 and $0.1 \mathrm{mg} / \mathrm{kg}$ doses. In contrast, in the other two phosphomutant lines, there was no difference between mutants and wild types in the number of infusions self-administered at any dose of cocaine.

\section{Phosphorylation of DARPP-32 in wild-type mice after cocaine self-administration}

We examined the phosphorylation state of Thr34-, Thr75-, Ser97-, and Ser130-DARPP-32 in the striatum from wild-type mice that had completed the cocaine self-administration procedures and in control mice that received yoked saline infusions. The amount of cocaine self-administered per session in this phosphorylation study ranged from 3.8 to $31 \mathrm{mg} / \mathrm{kg}$, and the average amount of cocaine self-administered on the last session was 23 $\mathrm{mg} / \mathrm{kg}$. As shown in Figure 4, cocaine self-administration significantly decreased P-Thr34- and P-Ser130-DARPP-32 in striatal homogenates. No significant changes were found in P-Thr75- or P-Ser97-DARPP-32 or in the levels of total DARPP-32 (data not shown).

\section{Attenuated increases of dopamine in the dorsal striatum of} Thr34A and Ser130A DARPP-32 phosphomutant mouse lines in response to acute binge cocaine administration

To examine the involvement of DARPP-32 in regulating dopamine release, we measured extracellular dopamine levels in the dorsal and ventral striatum in Thr34A-, Thr75A-, and Ser130ADARPP-32 phosphomutant and in mixed wild-type controls by in vivo microdialysis in response to binge pattern cocaine (20 $\mathrm{mg} / \mathrm{kg}$, i.p., three times at hourly intervals).

In the phosphomutant mice, binge cocaine administration produced increases in extracellular dopamine in the dorsal striatum compared with levels in mice given saline in a similar pattern (Fig. $5 a-d$ ). However, the percentage increase over baseline levels in extracellular dopamine after binge cocaine administration was significantly attenuated in the Thr34A- and in the Ser130ADARPP-32 phosphomutant mice compared with wild-type mice (Fig. 6a). No difference was found in percentage increase in dopamine levels after cocaine in the dorsal striatum of the Thr75ADARPP-32 phosphomutant mice compared with the wild-type controls.

Cocaine-induced increases in dopamine in the ventral striatum of the phosphomutant line and of wild-type control mice are shown in Figure $5 e-h$. Note the expected lower basal levels of dopamine in ventral striatum (nucleus accumbens) compared with dorsal striatum (caudate-putamen), as has been found in C57BL/6J and 129J mice (Zhang et al., 2001) and rats (Maisonneuve and Kreek, 1994). Mice of each phosphomutant line also showed significant increases in dopamine levels after binge cocaine administration (Fig. 6b). No significant differences between the Thr34A- or Ser130A-DARPP-32 phosphomutant mice and wild-type controls were found. However, Thr75A-DARPP-32 phosphomutant mice showed a greater percentage increase in levels of dopamine in response to binge cocaine administration than did wild-type controls.

\section{Discussion}

To identify intracellular signaling pathways involved in cocaine self-administration, we investigated the role of four distinct phosphorylation sites of DARPP-32 in cocaine selfadministration behavior. Thr34A-DARPP-32 mutant mice took a significantly longer time to reach self-administration criteria than did their wild-type controls. None of the other mutant mice showed this phenotype. Both the Thr34A- and Ser130A- 
a.

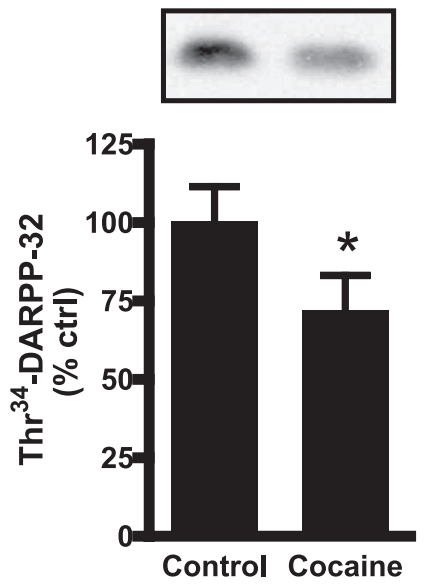

C.
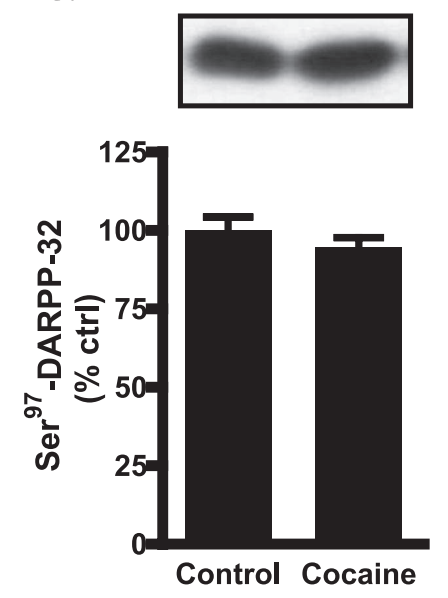

d.

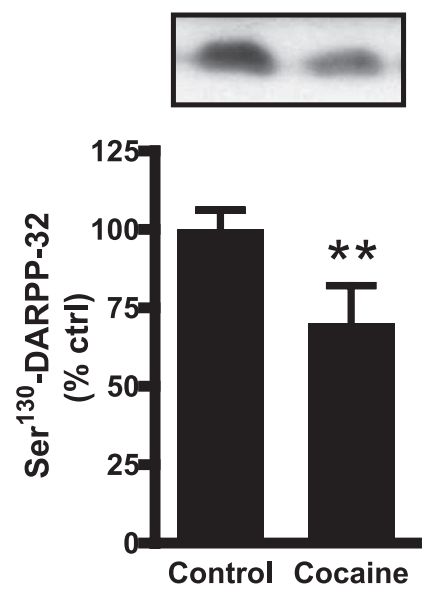

Figure 4. Regulation of phosphorylation of DARPP-32 in vivo by cocaine self-administration in wild-type mice. $\boldsymbol{a}-\boldsymbol{d}$, The levels of phosphorylation of Thr34-, Thr75-, Ser97-, and Ser130DARPP-32 and of total DARPP-32 were measured in striata of wild-type mice that had completed the cocaine self-administration paradigm and were compared with levels in control mice that received yoked saline infusions. Data are shown as means \pm SEM for seven mice per group expressed as a percentage of control values. Levels of P-Thr34-DARPP-32 (a) and P-Ser130DARPP-32 (d) were reduced in animals that had self-administered cocaine ${ }^{*} p<0.05$ and ${ }^{* *} p<0.02$, respectively; ANOVA followed by planned comparisons). There were no significant changes in the levels of P-Thr75-DARPP-32 (b), P-Ser97-DARPP-32 (c), or total DARPP-32 (data not shown).

DARPP-32 mutant mice self-administered significantly more cocaine at lower doses than did their wild-type controls.

Of particular relevance to the present study are the reports that DARPP-32 KO mice and Thr34A mutant mice showed significantly reduced conditioned place preference to cocaine ( $\mathrm{Za}-$ chariou et al., 2002, 2005). The fact that we found that the Thr34A-DARPP-32 mice took longer to meet criteria for acquisition of cocaine self-administration behavior provides evidence for a functional role of DARPP-32 in this cocaine-reinforced behavior. Moreover, the increased self-administration of lower concentrations of cocaine in Thr34A- and Ser130A-DARPP-32 mice may reflect an apparent need to self-administer more cocaine to achieve the rewarding effect of cocaine. This interpretation is consistent with our microdialysis findings (see below). It is interesting that Thr34A-DARPP-32-/- mice also required a longer time to meet full self-administration criteria, but Ser130ADARPP-32-/- mice did not, suggesting that phosphorylation at
Dorsal Striatum
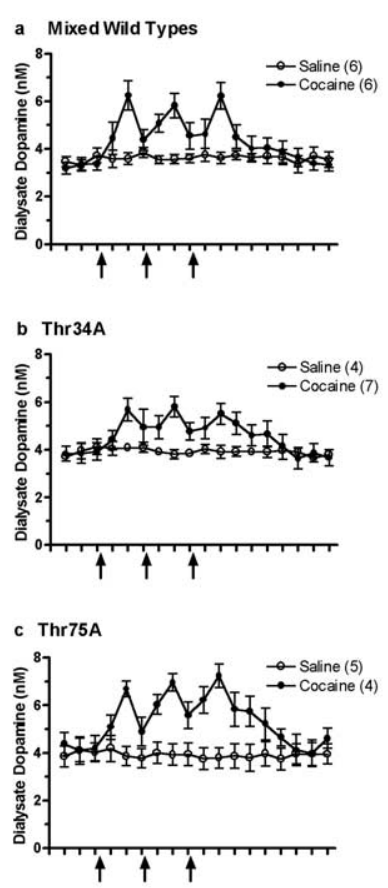

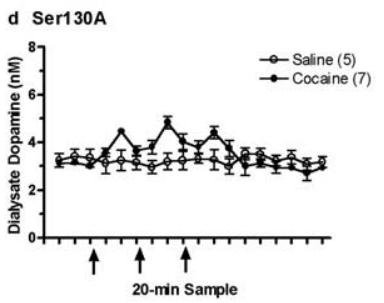

Ventral Striatum
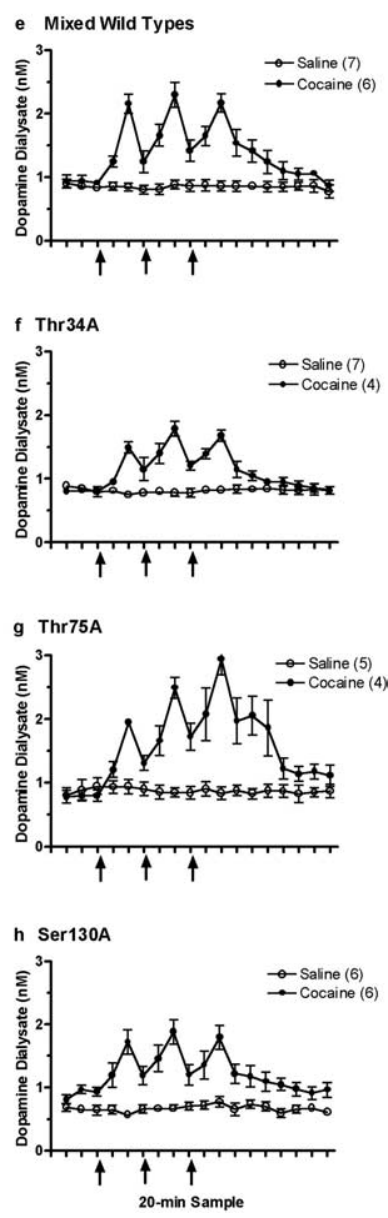

Figure 5. Levels of extracellular dopamine in two brain regions after binge cocaine administration in three lines of phosphomutant mice and in mixed wild-type controls. The number of mice in each experimental group is shown in parentheses. In the dorsal striatum, the mixed wild-type controls were two siblings from each of the Thr34A, Thr75A, and Ser130A lines for both the saline and cocaine groups. In the mixed control of the ventral striatum in the saline group, there were two Thr34A, three Thr75A, and two Ser130A siblings, whereas in the cocaine group, there were two Thr34A, three Thr75A, and one Ser130A siblings. $\boldsymbol{a}-\boldsymbol{d}$, The mean ( \pm SEM) levels of dopamine in the dialysate in each $20 \mathrm{~min}$ sample from the dorsal striatum before, during, and for $3 \mathrm{~h}$ after the last binge cocaine administration $(20 \mathrm{mg} / \mathrm{kg}$, i.p.; indicated by arrow) or saline administration. $\boldsymbol{e}-\boldsymbol{h}$, Levels of extracellular dopamine in the ventral striatum of the three lines of phosphomutant mice and the mixed wild-type controls.

Thr34A-DARPP-32 might be related to cocaine-associated learning processes.

The increased responses for lower doses of cocaine in Thr34Aand Ser130A-DARPP-32 phosphomutant mice found here are intriguing. The increased response to lower, but not higher, doses of cocaine in Thr34A- and Ser130A-DARPP-32 mice indicates that the rewarding effect of a given lower dose of cocaine is reduced in these mice. Additional evidence for a role of P-Thr34and P-Ser130-DARPP-32 in the actions of cocaine is the observation that the phosphorylation state of these residues is reduced in wild-type mice that had self-administered cocaine. The fact that P-Thr34-DARPP-32 is downregulated after selfadministration of cocaine is in agreement with a previous report (Bibb et al., 2001). The present behavioral and biochemical data suggest that the reduced levels of P-Thr34- and P-Ser130DARPP-32 after cocaine self-administration are parts of an adaptive negative feedback mechanism. These could be attributable to 

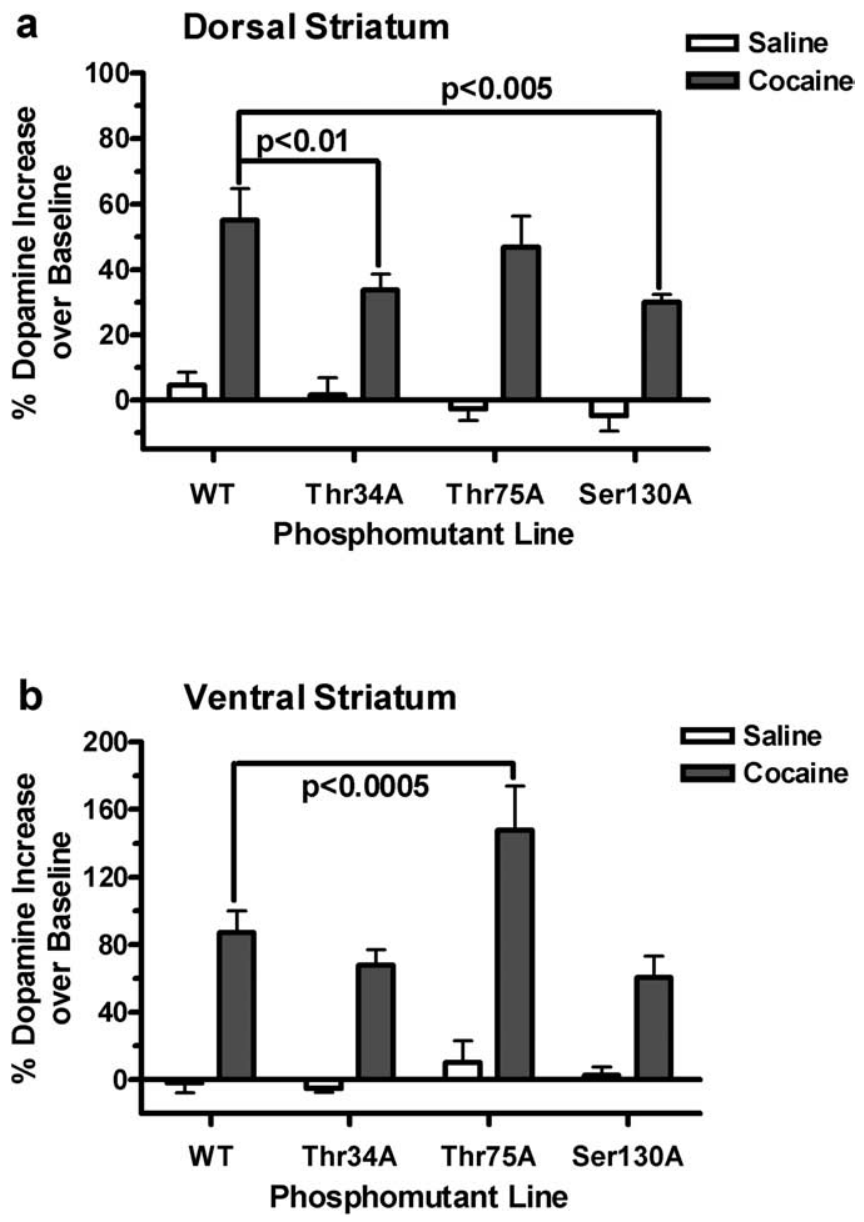

Figure 6. Dopamine levels in two brain regions after cocaine administration in three phosphomutant lines and their mixed wild-type controls. Data are shown as means ( \pm SEM) expressed as a percentage increase over mean baseline level during a $3 \mathrm{~h}$ interval ( $1 \mathrm{~h}$ after each injection). Binge pattern cocaine administration elevated dopamine levels in both brain regions compared with saline: main effect of cocaine, $p<0.05$ in the dorsal striatum and $p<0.001$ in the ventral striatum. However, in the dorsal striatum, attenuated increases of dopamine after cocaine administration were found in both Thr34A and Ser130A lines of phosphomutant mice compared with wild-type controls ( $\boldsymbol{a})(p<0.01$ and $p<0.005$, respectively; one-way ANOVA followed by planned comparisons). In the ventral striatum, there were significantly greater increases in levels of dopamine in response to cocaine in Thr75A phosphomutant mice compared with wild-type controls $(\boldsymbol{b})$ ( $p<0.005$; one-way ANOVA followed by Newman-Keuls post hoc tests).

decreased PKA and CK1 activities and/or increased PP-2B and PP-2C activities. Cocaine self-administration causes a persistent increase in PKA activity in the nucleus accumbens in rats (Lu et al., 2003), indicating that altered PKA activity may not underlie the changes in Thr34-DARPP-32 phosphorylation observed here. However, additional studies that would examine species differences, different self-administration protocols, and different time points after self-administrations are required to clarify the individual roles of Thr34 and Ser130 phosphorylation sites in cocaine self-administration.

Regardless of whether the reductions of P-Thr34- and P-Ser130-DARPP-32 depend on altered kinase or phosphatase activities, these phosphorylation changes are consistent with decreased DARPP-32 activity and thus increased PP-1 activity. It is well established that PKA-mediated phosphorylation at Thr34DARPP-32 and the conversion of DARPP-32 into an inhibitor of $\mathrm{PP}-1$ play a critical role in amplifying the phosphorylation state of numerous substrates, including receptors and ion channels that are regulated by PKA and PP-1 (Greengard, 2001). When stimuli are strong, as is the case with higher doses of cocaine, phosphorylation by PKA is sufficient to compensate for a deficiency of the DARPP-32 pathway. However, when stimuli are weaker, as is the case with the lower doses of cocaine used in this study, mice with an impaired DARPP-32 pathway caused by mutation of either Thr34- or Ser130-DARPP-32 show alteration in cocaine selfadministration behavior compared with wild-type controls. Activation of dopamine receptors by cocaine alters the cAMP/PKA/ DARPP-32/PP-1 signaling cascade, affecting the phosphorylation state of various substrates in the striatum and in turn providing feedback to the dopaminergic neurons. Previous studies showed that there is a reduction of dopamine release from striatal slices and a reduced toxic effect on dopamine terminals after administration of another psychostimulant, methamphetamine, in DARPP-32 KO mice (Fienberg et al., 1998). Using in vivo microdialysis studies, we found that both Thr34A and Ser130A mutant mice showed an attenuated increase in dopamine in the dorsal striatum after acute binge cocaine compared with wild types. In the rat, it has been shown that dopamine levels in the dorsal striatum were increased during cocaine-seeking behaviors (Ito et al., 2002). The attenuated increases of cocaine-induced dopamine in the dorsal striatum may partly explain why Thr34Aand Ser130A-DARPP-32 phosphomutant mice poked more often for cocaine than their wild-type controls at the lower doses of cocaine.

A previous study showed that chronic intermittent intraperitoneal administration of cocaine increased Cdk5 levels and Cdk5-mediated phosphorylation of DARPP-32 at Thr75 in striatal extracts consisting mostly of the caudate-putamen (Bibb et al., 2001). However, cocaine self-administration had no effects on Cdk5 levels in the rat nucleus accumbens (Lu et al., 2003) or P-Thr75-DARPP-32 in mouse dorsal striatum (present study). In the present study, the Thr75A-DARPP-32 mice did not show any behavioral difference in self-administration of cocaine from their wild-type controls. However, in the study of acute binge cocaine effects, the dopamine levels in the ventral striatum were significantly increased in the Thr75A-DARPP-32 mutant mice in response to the binge pattern cocaine administration and were not at all reduced in the dorsal striatum compared with wild-type controls. This may partly explain why Thr75A-DARPP-32 mutant mice did not need to self-administer more cocaine when lower doses of cocaine were available.

Additional experiments are required to define the role of Ser97-DARPP-32 in the actions of dopamine. 129Sv/C57BL6 hybrid mice were used in these studies, and it is possible that a congenic background is necessary to reveal a phenotype in the Ser97A-DARPP-32 mice. It will, for example, be of interest to characterize cocaine-induced increases of dopamine in the dorsal and ventral striatum in such mice. In addition, it will be interesting to measure P-Thr34- and P-Ser130-DARPP-32 in the ventral and dorsal striatum separately to determine whether a difference exists in the P-Thr34- and P-Ser130-DARPP-32 between those brain regions.

In conclusion, the results of these studies show that mice with a specific mutation at the Thr34 site of DARPP-32 are slower in acquisition of cocaine self-administration; Thr34A- and Ser130A-DARPP-32 mutant mice self-administer more cocaine at lower doses; cocaine self-administration reduces P-Thr34- and P-Ser130-DARPP-32; and, in Thr34A- and Ser130A-DARPP-32 mice, there are attenuated increases in dopamine levels in the dorsal striatum induced by binge pattern cocaine. These data suggest that phosphorylation of Thr34- and Ser130-DARPP-32, 
regulated by $\mathrm{PKA} / \mathrm{PP}-2 \mathrm{~B}$ and $\mathrm{CK} 1 / \mathrm{PP}-2 \mathrm{C}$, respectively, are involved in adaptations that underlie the reinforcing effects of cocaine.

\section{References}

Andersson M, Usiello A, Pozzi L, Dominguez C, Borgkvist A, Fienberg AA, Svenningsson P, Fredholm BB, Borrelli E, Greengard P, Fisone G (2005) Essential role of PKA phosphorylation site of DARPP-32 in cannabinoid action. J Neurosci 25:8432-8438.

Bergasa NV, Mohajer B, Maisonneuve IM, Ho A, Maidment NT, Olive F, Gunduz M, Kreek MJ (1997) Basal total opioid peptide release in the striatum of rats with cholestasis from bile duct resection: a study by the use of in vivo microdialysis. Life Sci 61:1169-1175.

Bibb JA, Snyder GL, Nishi A, Yan Z, Meijer L, Fienberg AA, Tsai LH, Kwon YT, Girault JA, Czernik AJ, Huganir RL, Hemmings Jr HC, Nairn AC, Greengard P (1999) Phosphorylation of DARPP-32 by Cdk5 modulates dopamine signalling in neurons. Nature 402:669-671.

Bibb JA, Chen AC, Taylor JR, Svenningsson P, Nishi A, Snyder GL, Sagawa ZK, Ouimet CC, Nairn AC, Nestler EJ, Greengard P (2001) Effects of chronic exposure to cocaine are regulated by the neuronal protein Cdk5. Nature 410:376-379.

Desdouits F, Siciliano JC, Greengard P, Girault JA (1995) Dopamine- and cAMP-regulated phosphoprotein DARPP-32: phosphorylation of Ser137 by casein kinase I inhibits dephosphorylation of Thr-34 by calcineurin. Proc Natl Acad Sci USA 92:2682-2685.

Fienberg AA, Hiroi N, Mermelstein PG, Song W, Snyder GL, Nishi A, Cheramy A, O'Callaghan JP, Miller DB, Cole DG, Corbett R, Haile CN, Cooper DC, Onn SP, Grace AA, Ouimet CC, White FJ, Hyman SE, Surmeier DJ, Girault J, Nestler EJ, Greengard P (1998) DARPP-32: regulator of the efficacy of dopaminergic neurotransmission. Science 281:838-842.

Franklin KB, Paxinos G (1997) The mouse brain in stereotaxic coordinates. San Diego: Academic.

Girault JA, Hemmings Jr HC, Williams KR, Nairn AC, Greengard P (1989) Phosphorylation of DARPP-32, a dopamine- and cAMP-regulated phosphoprotein, by casein kinase II. J Biol Chem 264:21748-21759.

Greengard P (2001) The neurobiology of slow synaptic transmission. Science 294:1024-1030.

Hemmings Jr HC, Greengard P (1986) DARPP-32, a dopamine- and adenosine $3^{\prime}: 5^{\prime}$-monophosphate-regulated phosphoprotein: regional, tissue, and phylogenetic distribution. J Neurosci 6:1469-1481.

Hiroi N, Fienberg AA, Haile CN, Alburges M, Hanson GR, Greengard P, Nestler EJ (1999) Neuronal and behavioural abnormalities in striatal function in DARPP-32-mutant mice. Eur J Neurosci 11:1114-1118.

Ito R, Dalley JW, Robbins TW, Everitt BJ (2002) Dopamine release in the dorsal striatum during cocaine-seeking behavior under the control of a drug-associated cue. J Neurosci 22:6247-6253.

Koe BK (1976) Molecular geometry of inhibitors of the uptake of catecholamines and serotonin in synaptosomal preparations of rat brain. J Pharmacol Exp Ther 199:649-661.

Liu F, Ma XH, Ule J, Bibb JA, Nishi A, DeMaggio AJ, Yan Z, Nairn AC,
Greengard P (2001) Regulation of cyclin-dependent kinase 5 and casein kinase 1 by metabotropic glutamate receptors. Proc Natl Acad Sci USA 98:11062-11068.

Lu L, Grimm JW, Shaham Y, Hope BT (2003) Molecular neuroadaptations in the accumbens and ventral tegmental area during the first 90 days of forced abstinence from cocaine self-administration in rats. J Neurochem 85:1604-1616.

Maisonneuve IM, Kreek MJ (1994) Acute tolerance to the dopamine response induced by a binge pattern of cocaine administration in male rats: an in vivo microdialysis study. J Pharmacol Exp Ther 268:916-921.

Nishi A, Bibb JA, Snyder GL, Higashi H, Nairn AC, Greengard P (2000) Amplification of dopaminergic signaling by a positive feedback loop. Proc Natl Acad Sci USA 97:12840-12845.

Ouimet CC, Miller PE, Hemmings Jr HC, Walaas SI, Greengard P (1984) DARPP-32, a dopamine- and adenosine $3^{\prime}: 5^{\prime}$-monophosphate-regulated phosphoprotein enriched in dopamine-innervated brain regions. III. Immunocytochemical localization. J Neurosci 4:111-124.

Snyder GL, Girault JA, Chen JY, Czernik AJ, Kebabian JW, Nathanson JA, Greengard P (1992) Phosphorylation of DARPP-32 and protein phosphatase inhibitor-1 in rat choroid plexus: regulation by factors other than dopamine. J Neurosci 12:3071-3083.

Stoof JC, Kebabian JW (1981) Opposing roles for D-1 and D-2 dopamine receptors in efflux of cyclic AMP from rat neostriatum. Nature 294:366-368.

Svenningsson P, Tzavara ET, Carruthers R, Rachleff I, Wattler S, Nehls M, McKinzie DL, Fienberg AA, Nomikos GG, Greengard P (2003) Diverse psychotomimetics act through a common signaling pathway. Science 302:1412-1415.

Svenningsson P, Nishi A, Fisone G, Girault JA, Nairn AC, Greengard P (2004) DARPP-32: an integrator of neurotransmission. Annu Rev Pharmacol Toxicol 44:269-296.

Walaas SI, Aswad DW, Greengard P (1983) A dopamine- and cyclic AMPregulated phosphoprotein enriched in dopamine-innervated brain regions. Nature 301:69-71.

Zachariou V, Benoit-Marand M, Allen PB, Ingrassia P, Fienberg AA, Gonon F, Greengard P, Picciotto MR (2002) Reduction of cocaine place preference in mice lacking the protein phosphatase 1 inhibitors DARPP 32 or Inhibitor 1. Biol Psychiatry 51:612-620.

Zachariou V, Sgambato-Faure V, Sasaki T, Svenningsson P, Berton O, Fienberg AA, Nairn AC, Greengard P, Nestler EJ (2005) Phosphorylation of DARPP-32 at Threonine-34 is required for cocaine action. Neuropsychopharmacology, in press.

Zhang Y, Schlussman SD, Ho A, Kreek MJ (2001) Effect of acute binge cocaine on levels of extracellular dopamine in the caudate putamen and nucleus accumbens in male C57BL/6J and 129/J mice. Brain Res 923:172-177.

Zhang Y, Butelman ER, Schlussman SD, Ho A, Kreek MJ (2004) Effect of the endogenous kappa opioid agonist dynorphin $\mathrm{A}(1-17)$ on cocaine-evoked increases in striatal dopamine levels and cocaine-induced place preference in C57BL/6J mice. Psychopharmacology (Berl) 172:422-429. 